\begin{tabular}{|c|cc|c|}
\hline \multicolumn{3}{|c|}{ PORT SAID ENGINEERING RESEARCH JOURNAL } \\
\hline
\end{tabular}

\title{
Smart Breathing Walls for Integrated Ventilation: Heat Exchange and Indoor Air Quality Improvement
}

\author{
Dalia El Gheznawy ${ }^{1}$, Osama Abo El Enein ${ }^{2}$, Ghada Shalaby ${ }^{3}$ and Amany Saif ${ }^{4}$ \\ Received: 26 March 2020; Accepted: 28 June 2020
}

\begin{abstract}
There are many ideas and applications for incorporating nature into buildings to improve the quality of the indoor air and to achieve a higher percentage of natural ventilation with pollution reduction. One such idea is to use the Breathing Walls "BW" built on porous materials. The energy used in air-conditioned buildings is reduced by these materials. BW suggests a conceptual design suitable for hot climates and capable of controlling airflow across the entire surface and refrigerating internal spaces in various cooling ways. BW forming all or part of an air-permeable building envelope or exterior provide a comprehensive solution to the severe issue of self-inflicted environmental harm that many cities now face. BW are the walls that have pores inside them and can diffusion water vapor and helping to get rid of moisture and raise indoor air quality (IAQ). In both social and economic contexts, IAQ is a significant issue. The definition of breathing walls, their characteristics, and the environmental problems solved using BW will be discussed in this paper, as well as their impact on the improvement of the indoor air quality.
\end{abstract}

KEYWORDS: Breathing walls, Porous walls, Natural ventilation, Indoor air quality.

\section{INTRODUCTION}

The building envelope strongly contributes to obtaining a suitable environment inside the buildings because it is the link between the outside and the interior. Studies have increased on the materials and techniques of the buildings, and how it is suitable for the worst climatic conditions to achieve the comfort of the occupants of the building. In this paper, one of these techniques will be studied [1].

A well designed and constructed wall is a vital part of the home and has a far-reaching impact on occupant safety. A properly constructed wall should be configured to offer the following benefits:

A. Self-regulation of moisture year-round.

B. Storage of heat in winter and cool in summer.

C. Optimally-phased distribution of heat and cool.

D. Radiant heating and cooling [2].

Design decisions, materials selection, and construction practices are factors that influence the performance of buildings. Since buildings are created as a means of protection from outdoor conditions, and to provide amenities that would increase the user's comfort and wellbeing. It is essential to monitor the factors, which may unintentionally pose moderate to significant health risks on

${ }^{1}$ Lecturer of Architecture and Urban Planning Department - Faculty of Engineering - Port Said University -dalia.mohamed@eng.psu.edu.eg

${ }^{2}$ Associate Professor of Architecture and Urban Planning DepartmentFaculty of Engineering-Port Said University-Aboeinen@hotmail.com.

${ }^{3}$ Architect at CHP Company, corresponding author, Gshalaby.gs@gmail.com.

${ }^{4}$ Lecturer of Mechanical Power Engineering Department - Faculty of Engineering - Port Said University - amanysaif@eng.psu.edu.eg

DOI: $10.21608 /$ pserj.2020.25973.1038 occupants. Indoor Environmental Quality (IEQ) refers to the quality of the built environment concerning the health, and wellbeing of the building's occupants. The factors that contribute to IEQ include thermal comfort, IAQ, acoustic performance and visual comfort. Sources of indoor contaminants that contribute to poor IAQ include outdoor sources as well as indoor sources such as activities, building materials, and furnishings. With the introduction of chemicals in the building industry. Therefore, the investigation of the combined effect of these contaminants is essential [3].

As properly understood, the "breathing wall" is an extremely important concept for high IAQ and mold-free construction. Unfortunately, some people interpret the expression literally, but the words "breathable" and "breathability" apply to the porous fabric intended for moving water as vapor but not as a liquid [2].

BW the definition of "breathing / breathable walls" is used to signify walls that are capable of diffusing water vapor to improve the indoor air quality (IAQ) that reaches users within the building using natural or industrial materials or both of them [4].

The quality of indoor air is a major concern from both a social and an economic viewpoint. There are many architecture approaches that can be put in to successful IAQ delivery. If used as part of a holistic design strategy, regulated ventilation, proper planning, and the use of suitable safe building materials may provide good indoor air quality. The so-called "breathing walls" or porous walls will reduce indoor humidity as part of a full IAQ design strategy and effectively eliminate the potential for fungal growth on building surfaces [5].

This paper will address the idea of breathing walls, their features and the environmental issues these walls solve, as well as their impact on improving indoor air quality. 


\section{FACTORS INFLUENCING INDOOR AIR QUALITY"IAQ"}

The internal environment of any built facility is the result of communication between the location, the climate, construction structure (original design and subsequent structural and mechanical structure modifications), construction methods, sources of pollutants (building materials and furnishings, soil, constructed processes and operations, and external sources) and construction occupants [6].

Ventilation and contamination are the two main contributors to IAQ as shown in Fig.1. Ventilation is determined by outdoor fresh air supply and indoor air circulation (mechanical systems). Thermal comfort conditions defined by temperature, humidity, and airflow are affected by ventilation. The contamination of indoor spaces can be the result of introducing outdoor pollutants through windows and doors. Other sources of contaminants are determined by the emission rates from indoor sources including furnishings, materials as well as human activities. Building materials contribute to indoor contaminants [3]. Consideration must be provided to the role that each of these factors can play in preventing and resolving indoor air quality problems [6].

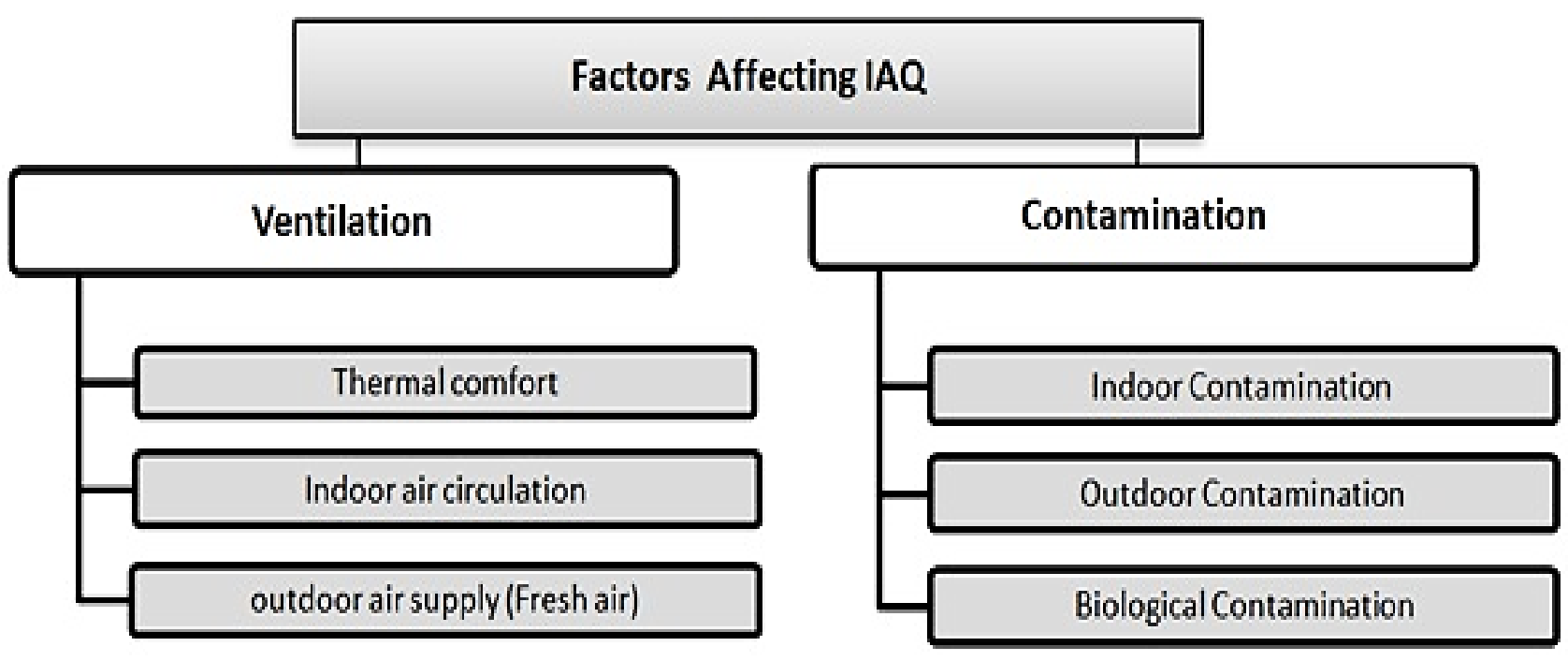

Figure. 1: Factors Affecting IAQ [3].

\subsection{Causes of Indoor Air Pollution}

Indoor air pollution has an important effect on people's comfort, health, and performance. The main categories of contaminants in indoor environments are inorganic contaminants, organic contaminants, and particulate matter. Organic contaminants include bacteria, fungi, viruses, molds, pollen and dander that can impact air quality. Inorganic contaminants include emissions from adhesives, furnishings, floorings and wall coverings as well as other sources such as fuels, chemicals such as cleaners and combustion by-products. Particulate matter (PM) is classified into coarse, fine and ultrafine particles and is originated from dust, construction activity, combustion, smoking, and other outdoor and indoor activities [3].

Formaldehyde and $\mathrm{PM}_{2.5}$ (Particulate Matter) are well known pollutants that unfavorably aff ect human wellbeing. Past studies have found that introduction to high formaldehyde concentration can cause eye and nasal bothering, and long-range presentation may increment the chance of cancer. Additionally, other studies have clarified that presentation to high $\mathrm{PM}_{2.5}$ concentrations causes constant respiratory symptoms and even lung cancer.
These direct and indirect unfavorable eff ects are compounded by the truth that, individuals, as a rule, spend more than $90 \%$ of their time indoors. Hence, indoor discuss quality is an imperative figure in people's wellbeing and execution. For case, the indoor PM2.5 concentration is influenced by the outdoor PM2.5 concentration, which is changed with the seasons. The indoor $\mathrm{CO}_{2}$ concentration is aff ected by the number of individuals in an indoor space. Besides, the indoor concentrations of both poisons are significantly aff ected by ventilation rates, which moreover alter from season to season since of occupants' changing ventilation behaviors all through the year [7].

\section{The IAQ is usually influenced by three major classes of pollutants:}

i.Outdoor air contaminants, such as carbon monoxide (CO), benzene $\left(\mathrm{C}_{6} \mathrm{H}_{6}\right)$, sulfur dioxide $\left(\mathrm{SO}_{2}\right)$, ozone $\left(\mathrm{O}_{3}\right)$, nitrogen oxides $\left(\mathrm{NO}, \mathrm{NO}_{2}\right.$ ), and particles breaching the building's surface or entering the building through windows or air handling systems (AHU) such as pollen, dust, fungal spores, agricultural contaminants, general vehicle exhaust, dumpster odors and soil gas (Radon, contamination from, underground fuel tanks, site pollutants (e.g., landfills) and pesticides)[6,8]. 
ii.Those primarily produced in households, to be specific occupant-related toxins like $\mathrm{CO}_{2}$, bio-eff uents and particulate matter (PM) in diff erent measure ranges [8] Such as Individual actions (smoking, cooking, body odor and restorative odors) [6].

iii.Building-related poisons, ordinarily unstable organics (VOCs) starting from e.g. Development fabric, furniture, and offi ce gear as well as microbial contaminants such as infections, organisms, and microbes.

The IAQ's affection by the intrusion of outside air into the indoor atmosphere often depends on the form and function of a building's ventilation system that may be natural, mechanical or hybrid [8].

\subsection{Problems of Mold and Condensation and Causes of Their Formation}

Molds and Fungi blocks that grow on the surfaces of objects, in pores and degraded materials. This can cause problems in color change and odor, leading to the deterioration of building materials and causing Allergy in sensitive people and other health problems. These terms are required for mold growth to happen on surfaces:

- A temperature range above $40^{\circ} \mathrm{F}$ and below $100^{\circ} \mathrm{F}$.

- Seeds of mold.

- Foundation of nutrients (most nutrients include surfaces).

- Humidity.

All widely used building materials and furniture may provide nutrients to help grow mold. Dirt on surfaces contains supplemental nutrients. Cleaning and sterilization with non-polluting cleaners and antimicrobial pads protect against mold growth [6].

Moisture is one of the most serious factors affecting building performance and durability, essentially in countries with cold climates. Understanding and predicting moisture movement inside and through the building enclosure is critical to managing and preventing moisture-such as erosion, freeze-and biological growth. Freeze-thaw issues related to moisture in the building structure include:

- Water intrusion into the building.

- Freeze-thaw oxidation of concrete, stone.

- Electrochemical corrosion of metal components such as structural framing included.

- Biological, especially fungal (mold) growth, which can damage materials and have an essential effect on occupant health.

- Chemical deterioration and dissolution of materials such as gypsum sheathing, glued wood products, etc.

- Volume changes (e.g., expansion, shrinkage), which can induce damaging stresses.

- Smearing and discoloration of building finishes [9].

\subsection{Take Steps to Reduce Humidity}

The growth of mold can be reduced by increasing the surface temperature in one or both of the following ways:

- Increase the temperature of the air in the vicinity of the room surfaces by either raising the thermostat setting or enhancing the circulation of the air so that the supply air is more efficient in heating room surface.

- Minimize heat loss from room surfaces either by adding insulation or by closing cracks in the outer wall to prevent wind from blowing (air entering a wall outside and leaving another outside without entering the building [6].

- Investigating new materials, which can break down harmful contaminants that helps mold appears, materials with hygroscopic properties (such as breathing walls BW), which can maintain the level of Relative Humidity (RH) within moderate levels and thus, it prevents the appearance of mold and improves the quality of indoor air [3]. The concept of $\mathrm{BW}$ will be explained in the next part.

\section{DEFINITION OF "BREATHING WALLS, (BW)"}

The definition of "breathing / breathable wall" is the walls that have pores inside it that are capable of diffusing water vapor to improve the indoor air quality (IAQ) that reaches users within the building using natural or industrial materials or both."

BW propose conceptual design suitable to hot climate and able to controlling airflow through the whole surface and cooling internal spaces in different cooling ways. BW are a biological approach in construction that aim to enhance the thermal behavior of traditional facades while creating a dynamic thermal atmosphere within architectural spaces [4].

Correctly breathing walls or "permeable walls' can be integrated with heating, ventilation and industrial air conditioning systems (HVAC) and reduce their overall dependence on them thus saving energy and electricity to them in addition to filtering the air in the fabric of the building itself before entering. The resulting breathable buildings are simple, elegant and sustainable to implement. A BW cladding panel can appear to the casual observer to be indistinguishable from any traditional building cladding [10].

For example, Fig.2 shows one of the sections of BW, which consists of three layers presented by Craig, 2017[11]:

- Rain screen: Weatherproofing and wind buffering can be done by outside rain-screen (made of the same fabric).

- BW: In common, any base fabric can be utilized as long because it can be created with channels of a millimeter long.

- The inner layer "fluid panel": A suitable coating should be applied to the inner wall because some coatings such as epoxy or rubber paint will close the pores inside the wall and thus prevent the three modes of transmission of moisture (water Vapor Permeability and diffusion, Hygroscopicity and Capillarity [2]. 


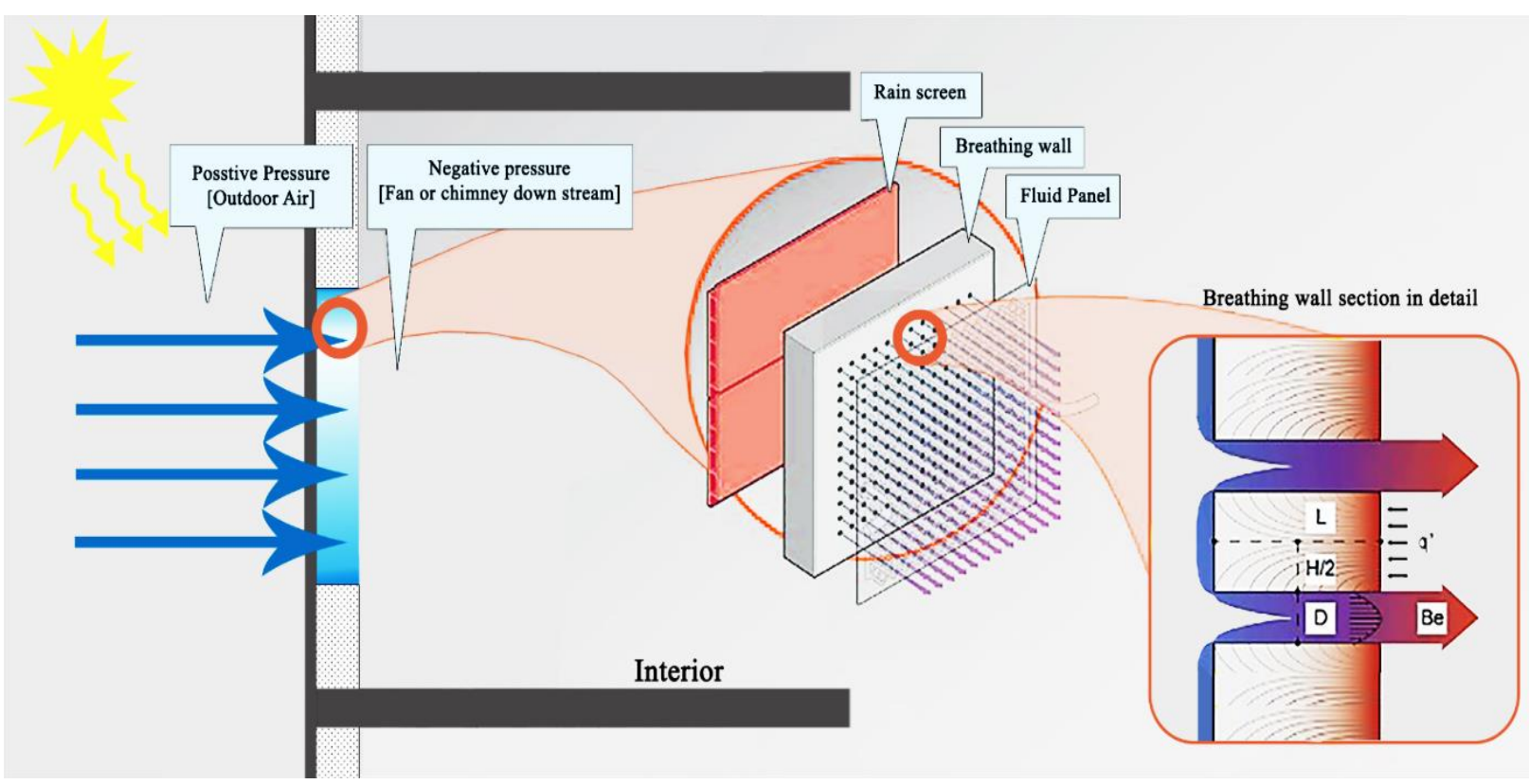

Figure. 2: Example of the building's enclosure with an enhanced "BW" porosity material for heat exchange with the inside air [11].

Ventilation air thus flows indoors through a BW when a pressure difference is applied, picking up conduction heat loss as it flows through the wall, with filtration of airborne pollutants occurring simultaneously [10].

The BW concept reduces complications over conventional building construction yet delivers significant gains in performance when part (or all) the façade of the building is transformed into an active, integrated part of the environmental control system of the building. Safely less energy is used in keeping the building warm (or cool) since the wall is now a heat recovery device. Moreover, the intimate coupling between indoor and outdoor environments that is a feature of breathing walls means that breathing buildings now can scrub (filter) ventilation air and exhaust clean air, thus safely reducing the overall level of airborne pollution in urban environments. Built-in a modular format, this ensures that even the most contaminated sites can be cost-effectively built or retrofitted for a wide variety of construction applications in the future. That means it will be possible in the future to provide our children and future generations with superior quality, healthy indoor and outdoor environments in our cities [10].

For the building to breathe and adapt to climate change, it must be equipped with intelligent ventilation systems that enable it to respond to changes that may occur in the future rather than using mechanical ventilation that increases energy consumption and carbon emissions [12].

BW definition has two sides:-

- Breathing from the biological side.

- Breathing on the architectural side.

\subsection{Breathing from the Architectural View Side}

The movement of the air in the buildings is known as ventilation. As in objects, the process of breathing represents the movement of air from the external environment to the respiratory devices of the object to supply it with oxygen and expels the carbon dioxide and the rest of the unwanted gases. The ventilation is the movement of air from the outside perimeter of the building into the inner spaces to be supplied with clean air and disposal of pollutants and excess heat [13].

\section{CHARACTERISTICS OF BREATHING BUILDINGS}

The building is similar to the living organism in several things. Comparing the transmission of air in the building with the living organism, it can be found that the air moves from the high-pressure spaces to the spaces with the least pressure, as in the process of inhalation and exhalation in most organisms, where the air moves because of the disparity in pressure from and to the lungs. Talking about breathing in buildings, both the air transmission and the water transfer are meant. They represent the most important relationship between the building and its external environment, which affects the health and the performance of the building.

The breathing buildings architecturally can be illustrated by two concepts (air transmission and water transmission).

\subsection{Air Transmission}

It refers to the natural ventilation of the buildings and the architectural means used to improve their performance. This is achieved through the organization and exploitation of the spaces of the building itself, in addition to the use of architectural solutions integrated with the building 
envelope, ceilings and floors. Natural ventilation is the movement of air from outside to the inside of the building, where the forces of nature such as wind pressure differences and temperatures on the movement of air from outside the building to the internal spaces through the openings in the building's envelope, which includes windows, doors, air intake, and others, then the air are distributed through the distribution routes represented by the different spaces of the building until they reach the exit, which may be through windows or doors and others. The natural ventilation depends on the climate. The building design and the behavior of building users [13].

\subsection{Water Transmission}

Water affects the building from the beginning of the quality of its cover and materials used in construction through the efficiency of the thermal performance of the building and even the health of its users. The strategy for dealing with water in the air and the fabric is therefore central to the success or failure of the building as a structure that endures, implements, and protects - i.e. the main functions of buildings. Good, strong and functional buildings can only be created by design with a full understanding of ventilation, which is the secret to determine whether construction design is effective or not [14].

Three main aspects should be cleared and applied if the effect of water on buildings is to be fully considered. These are:-

I. Vapor permeability and diffusion.

II. Hygroscopicity (absorption/adsorption).

III. Capillarity (absorption/adsorption) [2]. See table 1

Table 1: Effect of water in building [2].

\begin{tabular}{|l|l|}
\hline $\begin{array}{l}\text { Vapor } \\
\text { permeability }\end{array}$ & $\begin{array}{l}\text { - Refers to a material's } \\
\text { capacity to let water vapor } \\
\text { pass through it. }\end{array}$ \\
\hline Hygroscopicity & $\begin{array}{l}\text { Refers to water absorption } \\
\text { / adesorption as vapour (as } \\
\text { relative humidity changes). }\end{array}$ \\
\hline Capillarity & $\begin{array}{l}\text { - Refers to the absorption/ } \\
\text { adesorption of water as } \\
\text { liquid. }\end{array}$ \\
\hline
\end{tabular}

Adsorption: is a surface phenomenon and the effect of surface energy than the liquid or solid surface is in a state of strain or instauration that results in an unbalanced surface residual force. Such unbalanced residual forces result in greater energy from the air. Consequently, the liquid/solid surface often tends to attract and maintain the molecular species. The pattern is responsible for the adsorption phenomenon [15].

Absorption: is a physical or chemical phenomenon or a mechanism in which atoms, molecules or ions join a phase of bulk -solid or liquid. It is a different method from adsorption since the volume takes up the absorbing molecules, not the air. Adsorption is based on the surface where an absorption film is formed on the surface and involves the maximum volume of the absorbent agent in the absorption [16].

\section{DYMANIC INSULATION IN BW}

The building cannot be fully airtight, so IAQ must be considered to ensure occupant comfort: from here, air penetration contribute to reducing indoor pollution accumulation, vapor condensation risk, sick building syndrome risk [17].

$\mathrm{BW}$, which involves dynamic insulation, where fresh ventilation air is drawn through active or passive pressure differentials into the house, provides an attractive alternative that brings us closer to the concept of natural ventilation. The demonstrable benefits include improved energy efficiency by lowering the dynamic U-value of the building (dynamic U-value as a performance parameter for Breathing Walls, to be compared directly with the static Uvalue for traditional walls), the ability to deliver excessive average indoor ventilation levels without penalizing increased energy usage, Airflow controllability in the building and significantly reduced dependency on a large, costly, high-maintenance HVAC system. Also, BW will filter out 99.9 + percent of all airborne particulate matter, gaseous matter and other contaminants from the incoming ventilation air as part of a building's clean, maintenancefree system through the three characteristics previously mentioned in the breathing walls: vapor permeability, hygroscopicity and capillarity (absorption / adsorption).

This does not only mean that the inhabitants of buildings are safe from the harmful effects of airborne emissions, but also that these buildings clean up the outdoor environment in which they are located. In addition to its other advantages, the breathing wall encapsulates an important urban sanitation system capable of reversing the air pollution risks in cities around the world on a scale.

BW will eliminate unwanted moisture leaks in buildings. When cold ventilation air is drawn through the breathing wall into a warm house, the air flows in the opposite direction to the outside temperature as shown in Fig. 3. The backflow of mass versus heat flows causes cold air capture of heat that is usually lost by conduction, eventually resulting in a decreasing in the dynamic U-value of the wall and increased overall insulation efficiency [18]. 


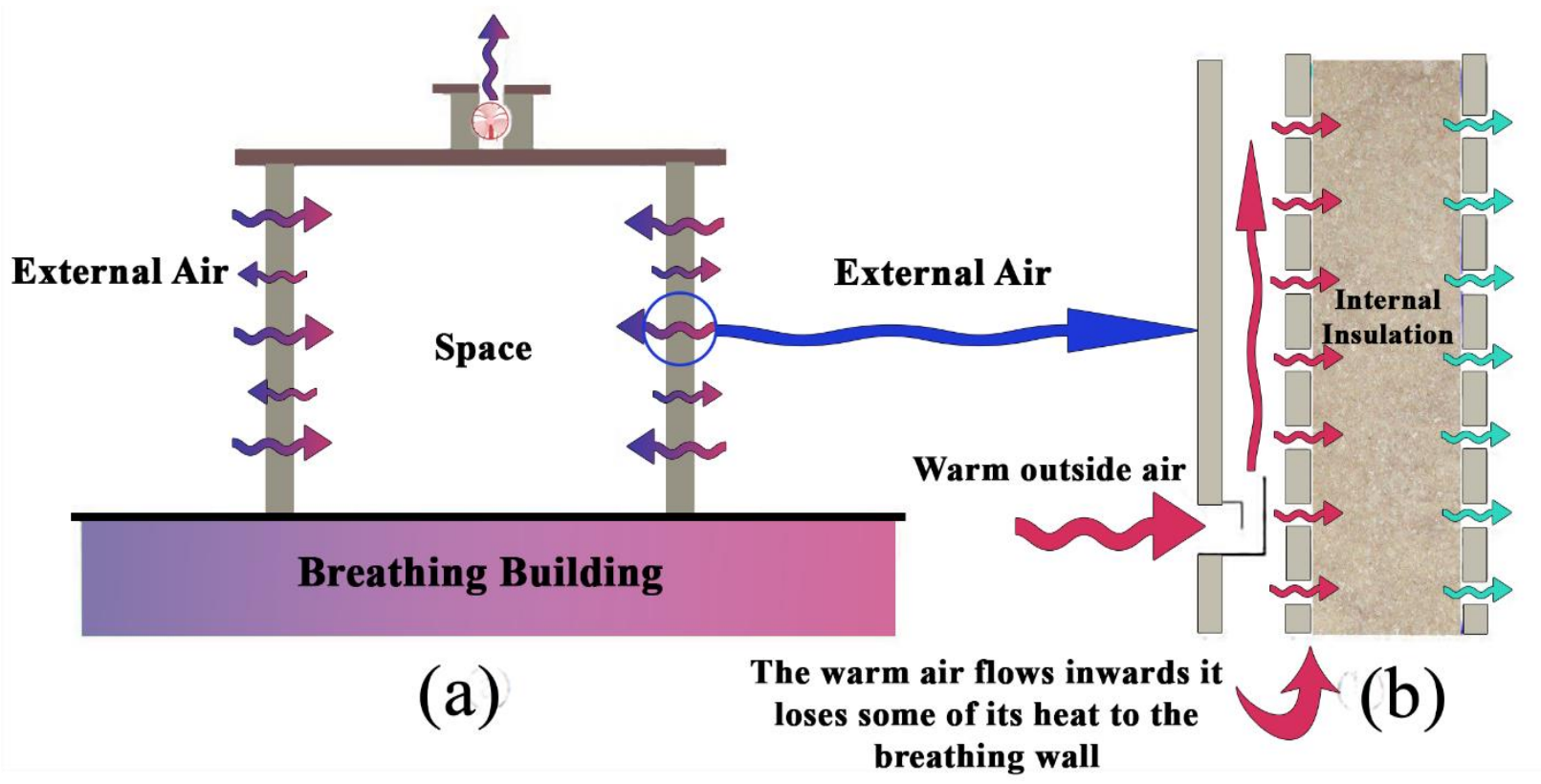

Figure 3: Heat and mass flow in (a) breathing building, and (b) BW [18].

It is vital for dynamic insulation to work optimally that incoming ventilation air flows uniformly through the widest possible area of a building or body's breathing space and reduces intrusion or leakage through gaps, cracks, leakage doors, windows, etc. [18]. The Dynamic Isolation system is made of easily penetrable and breathable components of the building enclosure. Often penetrable walls are called "breathing walls, BW" The term "dynamic isolation" refers to the alteration of the heat transfer mechanism due to airflow, and the two key characteristics of the dynamic isolation systems are:

1. Instead of injecting fresh air into the building through the delivery of air through the channels as in traditional heating, ventilation, and air conditioning systems, IAQ is guaranteed by ensuring adequate air flow through the walls.

2. The envelope moreover acts as an exceedingly effective particulate channel. As the circulating discussion is warmed or cooled agreeing to the working conditions, the dividers serve as a warm exchanger and these impact increments the vitality proficiency of the whole building system.

Therefore, dynamic insulation generates a "smart" thermal envelope, which plays a large role in the conservation of energy in buildings. Thus, in order to protect the domestic climate and save energy during heating and cooling activities, and to ensure proper maintenance of construction structures, appropriate studies are necessary to carefully evaluate the performance of envelope elements [17].

Dynamic insulation reduces connected heat losses by up to 50 percent. Therefore, dynamically insulated walls with thermal load can reduce the building's thermal load by about 20 percent [19]. Dynamic insulation provides a way of providing the interior with fresh filter ventilation air that brings us closer to perfect natural ventilation rather than bringing fresh air into the building using heating, ventilation and air conditioning systems, the air is drawn directly into the building through a dynamically penetrating enclosure [20]. See Fig.4
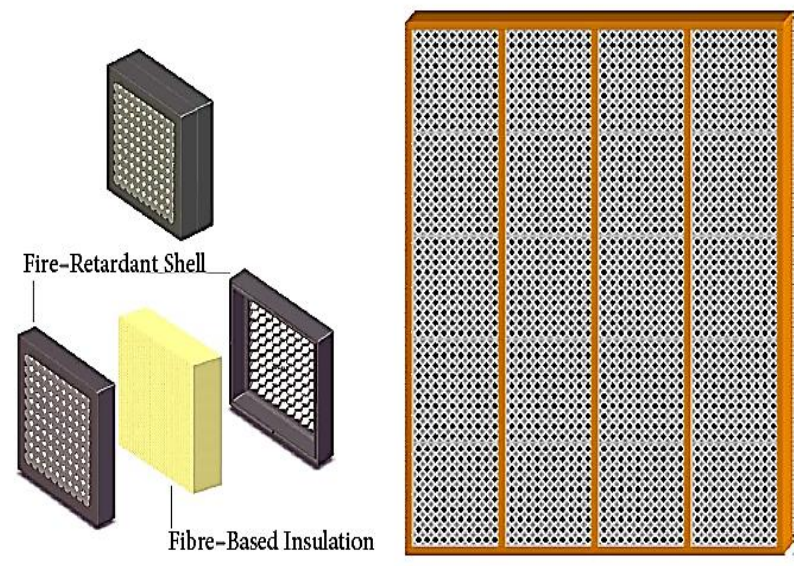

Figure 4: Modular breathing panel framed construction [21].

Dynamic insulation is hypothetically a kind of heat exchanger. The thermodynamics laws recommend a conceivable advantage for a warm exchanger that wraps a room: it may make it less demanding to use low-grade and renewable warm sources. Considering common materials, a few scientists contend that by controlling their inside geometry at distinctive length scales ready to progress the yield of straightforward constituent materials [11].

To operate correctly with dynamic isolation, the interior surface temperature must be carefully controlled. In theory, any essential material can be used as long as it can be made with millimeter air channels, such as wood, glass, or concrete. Wood planks achieved rates of heat recovery by 
approximately $100 \%$, while concrete and glass samples approached values closer to $60 \%$ [11].

For example, problems related to condensation and humidity can occur when there is insufficient ventilation of building materials and envelopes. By contrast, porous materials are well ventilated. We also have a constantly heated internal surface. Together, these features can allow faster and more efficient drying after periods of high humidity. The potential application is moisture-proof caching. Moisture caching occurs when porous material absorbs moisture in the net effect, stabilizing the material temperature and reducing the relative humidity inside the room. When completely dry and depending on the type of material used, it may be possible to drain the moisture negatively from inside through the heat exchanger wall. If the drying cycles of two or more rats are coordinated at different times, the effects of the moisture caching can be adjusted to increase occupant comfort and minimize energy use to the maximum [11].

\section{CONCLUDING REMARKS}

The Building Envelope is the relation between the exterior and the interior, which is responsible for providing the building's occupants with a good environment.

The IAQ for indoor air quality is a significant issue from both a social and an economic perspective. Several architecture approaches can be put to good IAQ execution. If used as part of a holistic design approach, regulated ventilation, proper planning, and the use of appropriate safe building materials can provide good indoor air quality.

The two principal contributors to IAQ are ventilation and pollution. Ventilation is determined by the fresh air supply outside and the circulation of indoor air (mechanical systems). Ventilation affects thermal comfort conditions which are characterized by temperature, humidity, and airflow. The contamination of indoor spaces may result from the introduction of contaminants from outside through windows and doors. Other contaminant sources are determined by indoor emission levels, including furnishings, fabrics, and human activities.

Building materials contribute to pollutants in the interior. It is necessary to consider the role that each of these variables can play in preventing, resolving and solving problems with the indoor air quality.

Moisture is one of the most important factors affecting building efficiency and durability, especially in coldclimate countries. Investigating new materials, which can break down harmful pollutants that make mold appear, materials with hygroscopic properties (such as breathing walls BW) that can maintain the degree of Relative Humidity $(\mathrm{RH})$ at moderate levels, thereby preventing mold emergence and enhancing indoor air quality.

Molds and mildew are organisms that develop on surfaces, inside pores, and in debased materials. These can cause discoloration and odor issues, fall apart building materials and cause unfavorably susceptible responses in individuals, as well as other wellbeing issues. For shape development to happen on surfaces, these conditions are vital: temperature extends over $40^{\circ} \mathrm{F}$ and underneath 100
${ }^{\circ} \mathrm{F}$, form spores, supplement base (most surfaces contain supplements) and humidity.

BW is the walls with pores inside which are capable of diffusing water vapor to boost the indoor air quality (IAQ) that reaches users inside the building using natural or industrial materials or both. "Architecturally, two principles should explain the breathing buildings: Air Transmission" Normal Ventilation, "and Water Transmission.

BW that requires dynamic insulation, where fresh ventilation air is drawn into the building using active or passive pressure differentials, provides an enticing solution that takes us closer to the natural ventilation ideal.

$\mathrm{BW}$ against the water but vapor permeable. BW help to get rid of moisture in the form of vapor through them because of the pores inside them. From here, we find that, BW are better than traditional walls in the thermal performance and relative humidity in the same conditions of temperature and pressure, BW is ideal for dry hot areas and hot wet areas with high relative humidity such as coastal places.

\section{Credit Authorship Contribution Statement}

Dalia El Gheznawy: validation, editing, review \& supervision. Osama Abou El Enein: review \& supervision. . Ghada Shalaby: conceptualization, original draft, methodology, resources and writing. Amany Saif: editing, review \& supervision

\section{DECLARATION OF COMPETING INTEREST}

The authors declare that they have no known competing financial interests or personal relationships that could have appeared to influence the work reported in this paper.

\section{REFERENCES}

[1] I. Abed Elrahman, "Effect materials and new technology on the design building envelope and improving interior environment", The Islamic University of Gaza, Master Thesis, 2015, p6.

[2] G. Swanson, "Breathing Walls, Biological Approach to Healthy Building Envelope Design and Construction", Book, 2008.

[3] D. M. Wagdi," Effect of Building Materials on Indoor Air Quality in Residential Buildings in Egypt: A pre Occupancy Assessment", The American University in Cairo, Masters of Science in Construction Engineering, 2015.

[4] M. Elghawaby, "Breathing façades: a new concept to create dynamic thermal ambiances in buildings located in hot climates", p. (214-218), 2012.

[5] J.F. Straube1 and V. Acahrya," Indoor Air Quality, Healthy Buildings, and Breathing Walls", Green Building Source, pp. (1, 2), 2003.

[6] Managers. Cincinnati, Ohio: NIOSH," Building Air Quality: A Guide for Building Owners and Facility", National Institute for Occupational Safety and Health (NIOSH), 1991.

[7] Liu, Junjie, et al. "Indoor air quality and occupants' ventilation habits in China: seasonal measurement and 
long-term monitoring." Building and Environment 142: 119-129, pp. (119, 120), 2018.

[8] Schieweck, Alexandra, et al. "Smart homes and the control of indoor air quality." Renewable and Sustainable Energy Reviews 94 (2018): 705-718.

[9] J. Frederick Straube," Moisture Control and Enclosure Wall Systems", A thesis submitted to the University of Waterloo for the degree of Doctor of Philosophy in Civil Engineering, Canada,1998.

[10] M. S. Imbabi, "New Developments in the science and art of breathing walls ", p. (1-6), 2004.

[11] S. Craig and J. Grinham. "Breathing walls: The design of porous materials for heat exchange and decentralized ventilation." Energy and buildings 149 (2017): 246-259, p. (247-256).

[12] S. Crawford, "Breathing Building Skin: Designing with the Concepts of Biological Adaptation", Master of Science in Design Computing, University of Washington, p. (212,213), 2010.

[13] M. Rezk," The concept of Breathing Buildings to cope with climate change", Cairo University, Master of Science, 2015.

[14] N. May," Breathability: The Key to Building Performance", p. (1-30), 2005.

[15] K. Parashar, "adsorption presentation", University of JOHANNESBURG, Department of applied chemistry, 2015.

[16] https://byjus.com/chemistry/adsorption-absorptiondifferences/, (C) 2018, BYJU'S, August 2018.

[17] Ascione, Fabrizio, et al. "Dynamic insulation of the building envelope: Numerical modeling under transient conditions and coupling with nocturnal free cooling." Applied Thermal Engineering 84 (2015): 1-14, p. (1-3).

[18] M. S. Imbabi and A. Peacock, "Smart Breathing Walls for Integrated Ventilation, Heat Exchange, Energy Efficiency \& Air Filtration", p. (2-5), 2003.

[19] M. Krarti, "Effect of air-flow on heat-transfer in Walls", (1994), p. (181,182).

[20] A.R. Brown, M.S.Imbabi and A.D.Peacock, "Dynamic Breathing Buildings to combat Global warming", International Solar Congress, p. (1-3), 2008.

[21] M.S. Imbabi,"Modular breathing panels for energy efficient, healthy building construction", Renewable Energy, p. (730-734), 2006. 